\title{
Improvement in Cutoff Frequency of Microstrip Butterworth Low Pass Filter using DGS Technique
}

\author{
Kalyan Acharjya, Dheeraj Acharya, Girijashankar Sahoo, Chandra Shekhar Rajora
}

\begin{abstract}
This paper presents the design, analysis and fabrication of Butterworth Low pass filter with sharp rejection response using defected ground surface technique. The work is carried out to design a low pass filter with cut-off frequency 2.5 $\mathrm{GHz}$ to achieved the broad frequency response; the first step is to make a rectangle of $10 \times 10 \mathrm{~mm}$ at ground surface and the equivalent circuit for the DGS, subsequently followed to consequent $L-C$ parameters extraction using analysis of $S$ parameters response (EM simulation). The designed Butterworth low pass filter is realized and optimized using DGS (Defected Ground Structure) to attain a compact size, satisfactory transition sharpness along with low insertion loss in pass band and wide rejection in the stop band. The fabricated device showed the good conformity with theoretical and VNA measured result.
\end{abstract}

Index Terms: Low Pass Filter, Micro strip Filter, Butter worth, Filter, DGS

\section{INTRODUCTION}

Filters have applications in various fields of engineeringand commonly used in various electronic devices to isolate noise or interference signal from surrounding environment. For instance, radio transmitter use filters to block harmonics release which may be interfering with other communication devices. A Microwave filter [10] is used to manage the frequency response at a certain point and have different types based on frequency range, e.g. low pass filter $[10,12]$ pass the lower frequency components (smaller than cutoff frequency) to pass while rejecting the higher frequency components.

Latest development in modern wireless communication systems has urged for new high-quality miniature filters design to support modern devices

\section{II.Desining Of Butter worth Low pass filter [10]}

Desining specification of $5^{\text {th }}$ order Butterworth Low pass filter using Insertion loss method are shown in table 1.

Revised Manuscript Received on December 30, 2019.

* Correspondence Author

Kalyan Acharjyahas, Department of Electronics and Communication Engineering, Jaipur National University, Jaipur (Rajasthan)

Dheeraj Acharya, M.Tech, Govt. Engineering College, Rajasthan

Girijashankar Sahoo, Associate Professor, Jaipur National University, Jaipur (Rajasthan) India.

Chandra Shekhar Rajora, Assistant Professor at Jaipur National University, Jaipur (Rajasthan) India.

(c) The Authors. Published by Blue Eyes Intelligence Engineering and Sciences Publication (BEIESP). This is an open access article under the CC BY-NC-ND license (http://creativecommons.org/licenses/by-nc-nd/4.0/)
TABLE1: DESIGNED FILTER PARAMETERS AND VALUES

\begin{tabular}{|l|l|l|}
\hline S.No. & Components & Value \\
\hline 1. & No. Of Element $(\mathrm{N})$ & 5 \\
\hline 2. & $\mathrm{R}_{\mathrm{S}}=\mathrm{R}_{\mathrm{L}}$ & $50 \Omega$. \\
\hline 3. & Cutoff frequency $\mathrm{f}_{\mathrm{c}}$ & $2.5 \mathrm{GHz}$ \\
\hline 4. & Substrate: GML & 1000 \\
\hline 5. & Permittivity of substrate $\mathrm{C}_{\mathrm{r}}$ & 3.2 \\
\hline 6. & Height h & $0.762 \mathrm{~mm}$ \\
\hline 7. & Size of substrate & $50 \times 50 \mathrm{~mm}$ \\
\hline
\end{tabular}

A. Technical Parameter of Butterworth LPF:

1. Insertion Loss/Attenuation loss: -

$N($ No. of Element $)=10 \operatorname{LOG}\left(1+w / w_{c}\right)^{2 N}$

2. CalculatingConductance: -

$$
\begin{aligned}
& g_{k=2 \sin \left[\frac{(2 k-1) \pi}{2 N}\right] \quad \text { where: }-K} \\
& =0,1,2 \ldots \ldots . N
\end{aligned}
$$

3. Inductance \&Capacitance: -

$$
\begin{aligned}
& \text { Inductance } L=R_{o} L_{p(g)} / w_{c} \\
& \text { Capacitancec }=\frac{C_{p}(g)}{R_{o} w_{c}}
\end{aligned}
$$

4. Electrical length of capacitor \& inductor

$\beta L_{\text {capacitor }}=\frac{C_{n} Z_{L}}{R_{o}} * \frac{180}{\pi}$

$\beta L_{\text {inductor }}=\frac{L_{n} R_{o}}{Z_{h}} * \frac{180}{\pi}$

Where: $-\mathrm{C}_{\mathrm{n}}=$ Normalized value of capacitor

$\mathrm{Z}_{\mathrm{L}}=$ Lower impedance

$\mathrm{R}_{0}=$ Source resistance

B. IMPLEMENTATION, ANALYSIS \& SIMULATION OF LOW PASS FILTER:

For design the low pass Butterworth filter [1, 2] using above mentioned formulae [10], we have followed the following steps-

Step 1: - Prototype design:

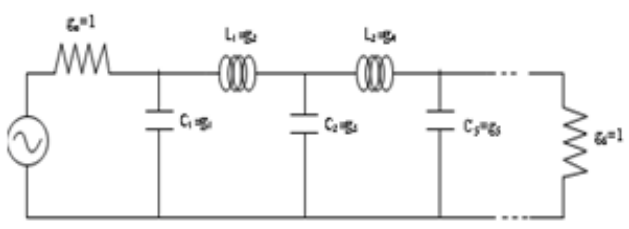

Figure 1: Schematic of LPF filter

Where:

$\mathrm{g}_{0}=1, \mathrm{~g}_{1}=0.6180, \mathrm{~g}_{2}=1.6180, \mathrm{~g} 3=2.000, \mathrm{~g}_{4}=1.6180$, $\mathrm{g}_{5}=0.6180, \mathrm{~g}_{6}=1$ 
Step 2:- Impedance and frequency scaling:

The original resistance $R_{n}$, inductance $L_{n}$ and capacitance $C_{n}$ are modified by the following formulae by effect of new load impedance of $R_{0}$ and cut-off frequency of $\omega_{0}$.

$$
\begin{aligned}
L=\frac{\left(R_{0} * L_{n}\right)}{\omega_{0}} & R=R_{0} R_{n} \\
& \mathrm{C}=\frac{\mathrm{c}_{\mathrm{n}}}{\mathrm{R}_{0} * \omega_{\mathrm{o}}}
\end{aligned}
$$

Using the transformation with $\mathrm{R}_{0}=50 \Omega$ and

$\omega_{0}=2 \pi\left(2.5 \times 10^{9}\right)$ the new values are: -

$\mathrm{C} 1=0.7872 \mathrm{pF} ; \mathrm{L} 2=\mathbf{5 . 1 5 2 8 \mathrm { nH }}$

$\mathrm{C} 3=\mathbf{2 . 5 4 7 7} \mathbf{p F} ; \mathrm{L} 4=\mathbf{5 . 1 5 2 8} \mathbf{n H}$

$\mathrm{C} 5=\mathbf{0 . 7 8 7 2} \mathbf{p F}$

\section{Step 3: Converting into distributed elements:}

The ratio $\mathrm{Z}_{\mathrm{H}} / \mathrm{Z}_{\mathrm{L}}$ should be as high as much possible, which is restricted by the practicaldesign, which can be implemented on a printed circuit board. Typical values are $\mathrm{Z}_{\mathrm{H}}=120$ to $150 \Omega$ and $\mathrm{Z}_{\mathrm{L}}=20 \Omega$ to $15 \Omega$, as a typical $\mathrm{LPF}$ design generally consists of irregular series inductors and shunt capacitors in a ladder configuration, here the design is implemented the filter on a PCB board by using variable high and low characteristic impedance section transmission lines [5]. Proposed design considered $Z_{L}=20 \Omega$ and $\mathrm{Z}_{\mathrm{H}}=120 \Omega$. The common relationship between inductance and capacitance with transmission line length are as follows (at the cutoff frequency $\omega_{c}$ ):

$\beta L_{\text {capacitor }}=\frac{C_{n} Z_{L}}{R_{o}} * \frac{180}{\pi}$
$\beta L_{\text {inductor }}=\frac{L_{n} R_{o}}{Z_{h}} * \frac{180}{\pi}$

Physical length $\mathrm{l}_{\mathrm{C} 1}$

$$
\begin{aligned}
& =(\text { Electrical length/360) } \\
& *\left(\mathrm{C} / \mathrm{f}_{\mathrm{c}} \sqrt{\varepsilon_{\mathrm{r}}}\right)
\end{aligned}
$$

$\mathrm{C}_{1}=2.820 \mathrm{~mm} ; \mathrm{L}_{2}=8.503 \mathrm{~mm} ; \mathrm{C}_{3}=9.126 \mathrm{~mm}$ $\mathrm{L}_{4}=8.503 \mathrm{~mm} ; \mathrm{C}_{5}=2.820 \mathrm{~mm}$

Table 2: Overall values of Microstrip Low-Pass Filter

\begin{tabular}{|l|l|l|l|l|}
\hline Element & $\begin{array}{l}\text { Element } \\
\text { Normalised } \\
\text { Value } \\
\left(\mathrm{g}_{\mathrm{k}}\right)\end{array}$ & $\begin{array}{l}\text { Actual } \\
\text { Element } \\
\text { Value }\end{array}$ & $\begin{array}{l}\text { Element } \\
\text { Value } \\
\text { Width } \\
(W) \mathrm{mm}\end{array}$ & $\begin{array}{l}\text { Length } \\
(L) \\
\mathrm{mm}\end{array}$ \\
\hline $\mathrm{C} 1$ & 0.6180 & $0.7872 \mathrm{pF}$ & 6.3524 & 2.820 \\
\hline L2 & 1.6180 & $5.1528 \mathrm{nH}$ & 0.5387 & 8.503 \\
\hline $\mathrm{C} 3$ & 2.000 & $2.5477 \mathrm{pF}$ & 6.3524 & 9.126 \\
\hline L4 & 1.6180 & $5.1528 \mathrm{nH}$ & 0.5387 & 8.503 \\
\hline C5 & 0.6180 & $0.7872 \mathrm{pF}$ & 6.3524 & 2.820 \\
\hline
\end{tabular}

Figure 2 :- Front Side of the Conductor Pattern

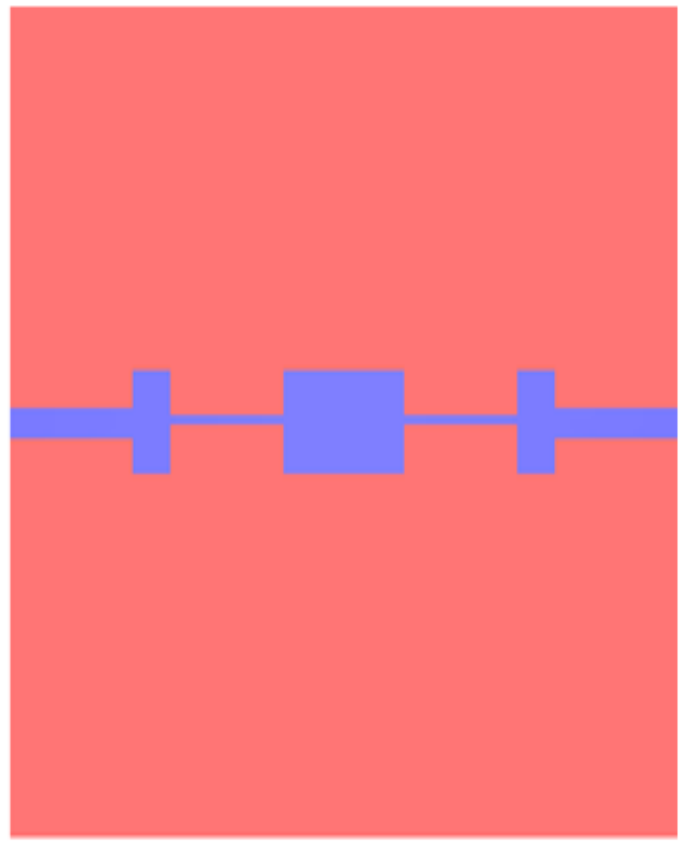

Figure 3 :-BackSide of the Conductor Pattern

\section{To Sharp Rejection Using Defected Ground Structure} $[1,2]$

The objective of structure like micro strip line with a centered slot at the ground plane has excellent applications in low pass filters for spurious band suppression which is called as Defected Ground Structure (DGS) [2, 3]. DGS adds an extra degree of freedom in microwave circuit design and opens the door to a wide range of application. It also added the slow-wave and band-stop features by varying the equivalent inductance and capacitance of the transmission line [13]. A compact Butter worth LPF [1, 2] with DGS and analyze the consequence of DGS parameter on the LPF. The size of DGS is $10 \times 10 \mathrm{~mm}$ in ground side of LPF. The front and back side of conductor prototype are shown in figure 2 and 3 respectively.

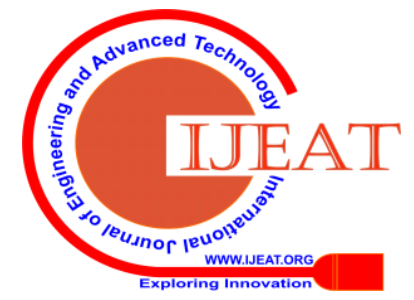




\section{SIMULATION RESULT}

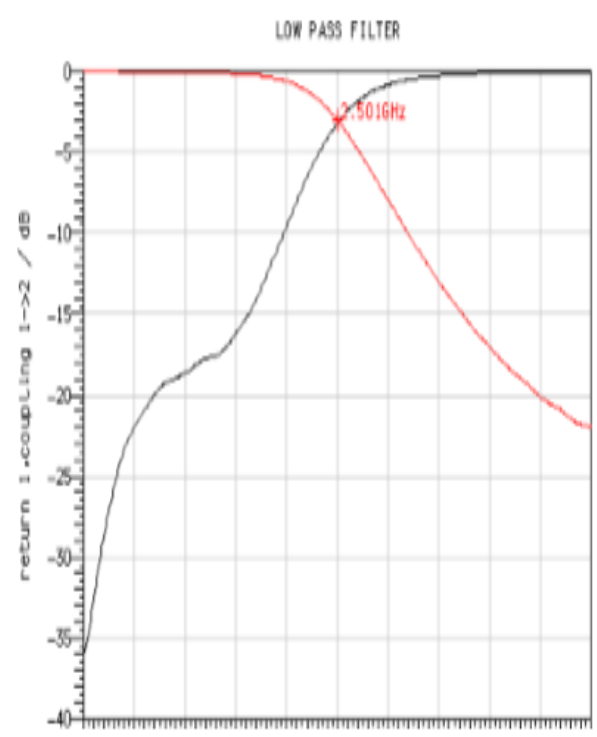

Figure 4: Responses of LPF with DGS (2.5 GHz)

\section{B. Measured Result Through Vna}

The response of the designed filter measured through vector network analyzer are shown in figure 6 and 7, and attained

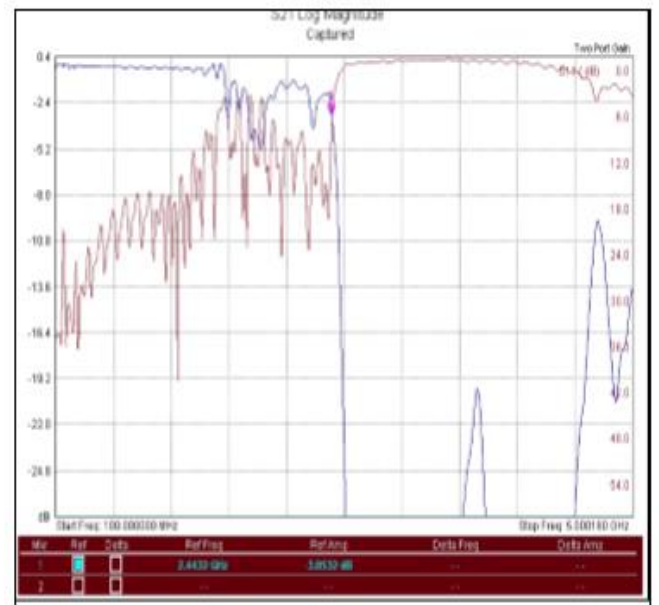

Figure 6: Result of LPF without DGS. (2.44 GHz)

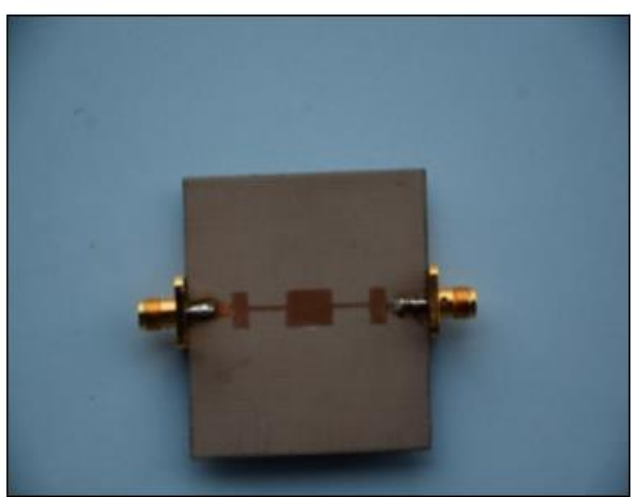

Figure 8: Front side of Fabricated Design
A. The response of the proposed design (with and without DGS) simulations results are shown in figure 4 and 5.

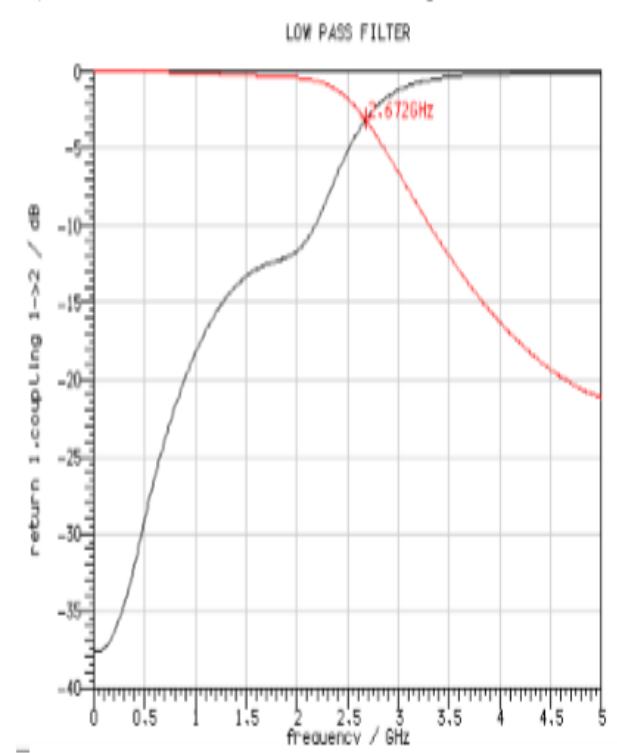

Figure 5: Responses of LPF with DGS (2.672 GHz)

the cutoff frequency $2.44 \mathrm{GH}_{\mathrm{Z}}$ for without DGS and 2.672 $\mathrm{GH}_{z}$ with DGS.

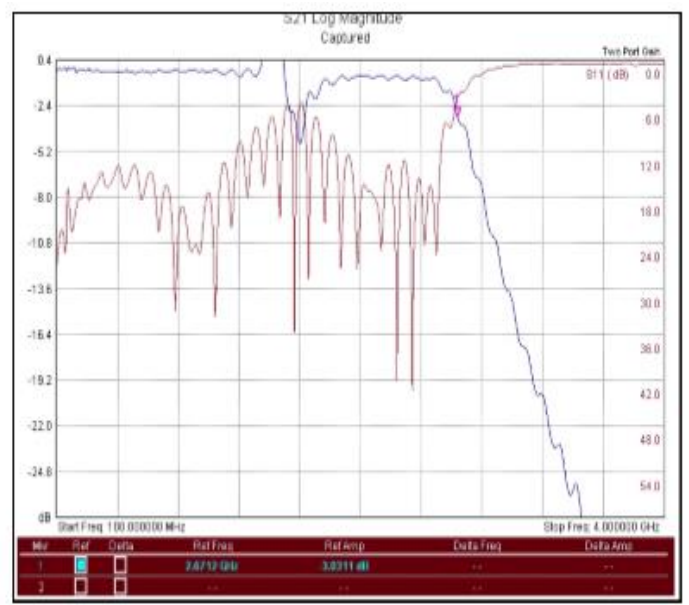

Figure 7: Responses of LPF with DGS (2.672 GHz)

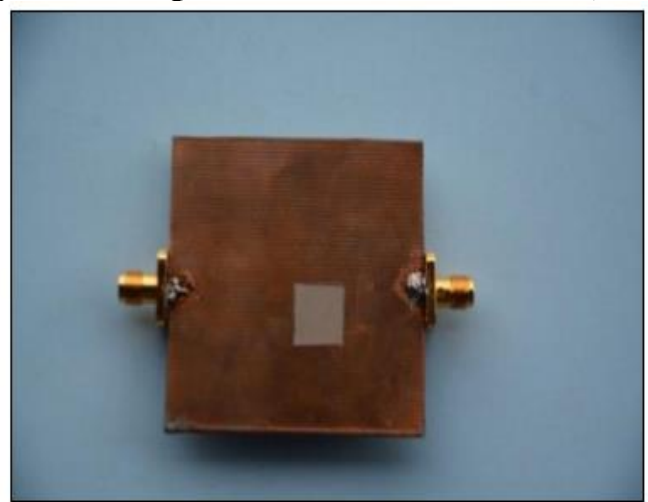

Figure 9: Back side of Fabricated Design 


\section{FABRICATION RESULT}

After Fabrication, authors measured the result of design whether it has attained the proposed specifications or not. The table 2 showed the comparison between simulations andmeasured result and it attains the target requirements. The fabricated design is shown in figure 8 and 9 for both side patterns.

Table 4: Comparison Results

\begin{tabular}{|c|c|c|}
\hline \multirow{2}{*}{ Parameter } & \multicolumn{2}{|c|}{ Simulated Results/ Measured Results } \\
\cline { 2 - 3 } & Before DGS & After DGS \\
\hline Cut Off & $2.5 \mathrm{GHz} /$ & $2.672 \mathrm{GHz} /$ \\
Frequency & $\mathbf{2 . 4 4} \mathbf{~ G H z}$ & $\mathbf{2 . 6 7 1} \mathbf{~ G H z}$ \\
\hline
\end{tabular}

\section{V.CONCLUSION}

The proposed work of Butterworth low pass filter with DGS was designedand fabricated. The presented $2.5 \mathrm{GHz}$ butter worth low pass filter have attained in the improvement up to 2. $672 \mathrm{GHz}$.The results obtained by manually by distributed parameters valuesusing formulae does not gave the satisfactory results as there was a large shift in the cut-off frequency because of various stray inductances and fringing capacitances in the filter design. But in the values of distributed parameters obtained after end corrections gave the results very close to the desire results. Thereafter to get the exact results, the designed was optimized [9] and it showed that by decreasing the inductance and corresponding length shifted the frequency to the right. The results obtained by Micro strip simulation arealmost same with fabricated device, while the measured results showed a slight shift in cut-off frequency due to fabrication errors.

\section{REFERENCES}

1. Jong-Sik Lim, Member, IEEE, Chul-Soo Kim, Member, IEEE, Dal Ahn, Senior Member, IEEE, Yong-ChaeJeong, Member, IEEE, and Sangwook Nam, Member, IEEE "Design of Low-Pass Filters Using Defected Ground Structure" IEEE Transactions On Microwave Theory And Techniques, vol. 53, no 8, Aug. 2005

2. Ortega, A. ; deMenezes, L.R.A.X.; Soares, A.J.M.; Abdalla,H. "Design of Low-pass Microstrip Filters based on Defected Grounds Structure" Microwave \&Opto electronics Conference (IMOC), 2011

3. Dal Ahn; Jun-Seok Park; Chul-Soo Kim ; Juno Kim ;Yongxi Qian; Itoh, T. "A Design of the Low pass Filter using the novel Micro strip Defected Ground StructureMicrowave Theory and Techniques", IEEE Transactions on Microwave Theory and Techniques, Vol. 49, No. 1, January 2001

4. Boutejdar, A. ; Omar, A. ; Batmanov, A. ; Burte, E."New LowPass Filter Design Using Compensated Microstrip Capacitor and Coupled Meander Defected Ground Structure ",German Microwave Conference, 2009.

5. Abdel-Rahman, A.B. ; Verma, A.K. ; Boutejdar, A. ; Omar, A.S.,"Control of band stop response of Hi-Lo micro strip low-pass filter using slot in ground", IEEE Transactions on Microwave Theory and Techniques, Vol. 52, No. 3, March 2004

6. Braunstein, J. ; Hyang-Beom Lee ; Jun-Seok Park ;Hyeong-Seok Kim "Design of a HarmonicRejection Microstrip LowPassFilter with Defected-Ground using Finite-Difference TimeDomainand Optimization Algorithms" 12th Biennial IEEE Conference Electromagnetic Field Computation, 2006

7. Boutejdar,A. ; Elsherbini,A. ; Omar,A.S. "A New Extraction Method using triangle Defected Ground Structure for the control of s-parameter response of hi-lo Microstrip Low-pass filter" Antennas and Propagation Society International Symposium, 2007.

8. Jin-Kyu Byun; Jae-Hyeong Ko; Hyang-Beom Lee ;Jun-Seok Park; Hyeong-Seok Kim Application of the Sensitivity Analysis to the Optimal Design of the Micro strip Low-Pass Filter With Defected Ground Structure", IEEE Transactions on Magnetics, Vol. 45, No. 3, March 2009

9. Krischuk,V.;Farafonov,A.; Shilo,G. ; Gaponenko,N. "Optimizationof microstrip filters tolerances",CAD Systems in Microelectronics-CADSM 2003, 2003.

10. David Pozar, "Microwave Engineering", John Wiley \& Sons, Third Edition, 2005

11. W. A. Davis, "Microwave Semiconductor Circuit Design", Van Nostrand Reinhold, NY, 1984

12. Jeffrey Frey, Kul Bhasin, "Microwave Integrated Circuits", Artech House, 1985.

13. Bharathi Bhat and ShibanK.Koul," Strapline like Transmission Lines for Microwave Integrated Circuits”. New Age International, 1989

\section{AUTHORS' PROFILES}

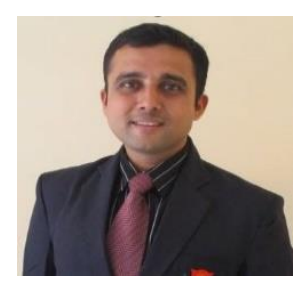

Kalyan Acharjyahas received his Master in Electronics Design and Technology from Tezpur University (CentralUniversity), India. $\mathrm{He}$ is currently associated withJaipurNational University, Jaipur in Departmentof Electronics and Communication Engineering. Hiscurrent research areas are Digital Image Processing, Antenna Design and VLSI Systems. He has vast experiences on MATLAB tool, and also holdinglife member ofIUPRAI.

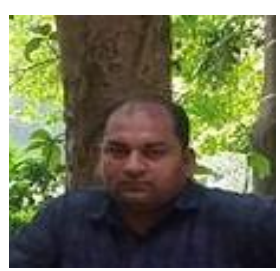

Dheeraj Acharya did his graduation from Bikaner Govt. Engineering College, Rajasthan. He has recently completed his M.Tech in Communication and Signal Processing from Jaipur National University. He has just started his research career in the field of Antenna Design, also he works on communication toolboxes for signal analysis and estimation.

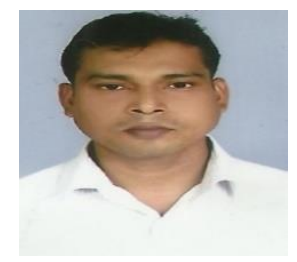

Girijashankar Sahoo has received his M. Tech degree in Digital Communication Engineering from Indian Institute of Information Technology, Gwalior, India in 2010.He is qualified UGC NET and GATE exam. He has published numerous research papers in reputed journals, IEEE conference proceedings etc. He also serves as reviewer in IEEE and Springer journals. Presently he is serving as an Associate Professor at Jaipur National University, Jaipur, India. His areas of interest include antenna design, adaptive signal processing, biomedical signal processing, cooperative communications and OFDM systems.

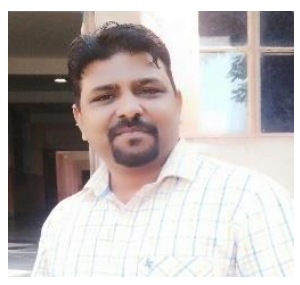

Chandra Shekhar Rajora received B.E.from Rajasthan University Jaipur,Rajasthan, India in 2005. At present he ispursuing M.Tech. in Digital Communication fromRajasthan Technical University. Presently he is serving as an AssistantProfessor at Jaipur National University, Jaipur, India. His special fields of interestare Optical Fiber Communication Systems and Antenna Design. 